\section{Radio Waves from Outside the Solar System}

IN a recent paper ${ }^{1}$ on the direction of arrival of high-frequency atmospherics, curves were given showing the horizontal component of the direction of arrival of an electromagnetic disturbance, which I termed hiss type atmospherics, plotted against time of day. These curves showed that the horizontal component of the direction of arrival changed nearly $360^{\circ}$ in 24 hours and, at the time the paper was written, this component was approximately the same as the azimuth of the sun, leading to the assumption that the source of this disturbance was somehow associated with the sun.

Records have now been taken of this phenomenon for more than a year, but the data obtained from them are not consistent with the assumptions made in the above paper. The curves of the horizontal component of the direction of arrival plotted against time of day for the different months show a uniformly progressive shift with respect to the time of day, which at the end of one sidereal year brings the curve back to its initial position. Consideration of this shift and the shape of the individual curves leads to the conclusion that the direction of arrival of this disturbance remains fixed in space, that is to say, the source of this noise is located in some region that is stationary with respect to the stars. Although the right ascension of this region can be determined from the data with considerable accuracy, the error not being greater than \pm 30 minutes of right ascension, the limitations of the apparatus and the errors that might be caused by the ionised layers of the earth's atmosphere and by attenuation of the waves in passing over the surface of the earth are such that the declination of the region can be determined only very approximately. Thus the value obtained from the data might be in error by as much as $\pm 30^{\circ}$.

The data give for the co-ordinates of the region from which the disturbance comes, a right ascension of 18 hours and declination of $-10^{\circ}$.

A more detailed description of the experiments and the results will be given later.

Bell Telephone Laboratories, Inc., KARL, G, JANSKY. New York, N. Y. May 8. 'Karl G. Jansky, "Directional Studies of Atmospherics at High
Frequencies", Proc. Inst. Rad. Eng., 20, $1920 ; 1932$.

\section{A Simple Hygrometer}

THE method described here has been developed to measure the humidity of the air in very small and inaccessible places. The hygrometer is extremely simple, consisting of a piece of paper $1 \mathrm{~cm} . \times 1.5 \mathrm{~cm}$. in size, weighing about $10 \mathrm{mgm}$. The paper has a hole at one end, by which it can be hung on to a torsion balance and weighed. Paper is a hygroscopic substance, which takes up an amount of water from the air proportional to the relative humidity, irrespective of temperature. The paper used (thin writing paper) increases in weight by 12 per cent when transferred from perfectly dry air to air which is 90 per cent saturated, and reaches equilibrium in 10-15 minutes. The torsion balance used is accurate to one-fortieth of a milligram, and the humidity can be measured accurately to 2 per cent.

The paper hygrometers should be kept in desiccators at 40 per cent relative humidity. If a number are made from one sheet of paper, it will only be necessary to calibrate one of them. The change in weight, after transferring from 40 per cent humidity, expressed as a percentage of the weight at 40 per cent, will be the same for all the hygrometers exposed to any particular humidity.

There are many applications for this method of hygrometry. It is possible to measure the humidity at the surface of a leaf, or among vegetation, without disturbing the air.

Kenneth Mellanby.

Department of Entomology,

London School of Hygiene and Tropical Medicine, Keppel Street, W.C.l.

May 26.

\section{Co-operative Industrial Research}

The leading article in NATORE of June 10 on this subject appears to me to be of profound significance. It brings into prominence the fundamental issues in regard to industrial research and the application of science to industry, which are so seldom taken into consideration.

I do not write in any critical spirit, but I feel that the end of the War left us-statesmen, administrators, scientific workers, and the nation at large-obsessed with the idea that the benefits to be derived from the application of science to industry were mainly external to the human mind and purely materialistic. We were very confident then that the so-called rationalisation of industry, the elimination of hand labour, the development of machinery and processes and the standardisation of mass-produced articles, were going to make us all happy and prosperous. A good many industrialists have learned since then that cheapness and efficiency in production are by no means everything; it is what is produced that matters most.

The vital thing about any manufactured product is the purpose it serves in the life of man, not the processes of its manufacture. Consideration of purpose leads to the investigation of design. Design is usually stated to include three factors, beauty, distinctiveness and utility. The relative importance of these factors will vary with the product, but it seems to me that to concentrate almost all industrial progress on utility, which is at present mainly affected by industrial research, may not give the highest true economic values.

At the same time, my experience has been that co-operative industrial research influencing the design of a product has been more appreciated and more readily and evenly utilised by firms of all sizes than research in other directions. The user, to whom the finished product is a design carried out in a certain raw material, has the last word in regard to research on design, but our present organisation of industrial research does not give him much representation on research committees. Again, it is clear that progress in industrial research depends on a scientifically minded consumer, who keeps abreast of developments in design.

I am afraid we have been inclined to look on the consumer as an ignorant or incompetent individual who will take what the manufacturer sees fit to provide. This is far from the truth to-day. Whether we like it or not, the rising generation is imbued with the scientific spirit and insists on absorbing and 